\title{
Subjetividade e ironia: breve discussão e análise
}

\author{
Subjectivité et ironie: brève discussion et analyse \\ Cristiane Dall Cortivo-Lebler \\ Universidade de Santa Cruz do Sul - Santa Cruz do Sul - Rio Grande do Sul - Brasil \\ Adilson Ventura da Silva \\ Universidade Estadual do Sudoeste da Bahia - Vitória da Conquista - Bahia - Brasil
}

$\diamond$

\begin{abstract}
Resumo: Este trabalho tem como objetivo discutir a concepção subjetiva de linguagem presente na Teoria da Argumentação na Língua, proposta por Oswald Ducrot e Jean-Claude Anscombre e desenvolvida nos dias atuais por Oswald Ducrot e Marion Carel. Abordaremos, ainda, o conceito de polifonia e o modo como a ironia é tratada segundo essa vertente teórica. Por fim, analisaremos uma crônica, na qual faremos a aplicação dos conceitos discutidos, com vistas à explicação do sentido polifônico.
\end{abstract}

Palavras-chave: Ironia; Subjetividade; Argumentação; Discurso

Résumé: Cet article a comme but, dans un premier moment, faire une discussion de la conception subjective du langage, qui appartienne à la Théorie de l'Argumentation dans la Langue, proposée initialement par Oswald Ducrot et Jean-Claude Anscombre, et développée aujourd'hui par Oswald Ducrot et Marion Carel. Fera-t-on, aussi, une discussion à propos du concept de polyphonie et à propos de la forme comme l'ironie est abordée selon cette théorie. Enfin, on analysera un discours humoristique, dans lequel on fera l'application des concepts qui ont d'abord été discutés, avec l'objectif d'expliquer le sens polyphonique de ce discours.

Mots-clé: Ironie; Subjectivité; Argumentation; Discours

\section{Palavras iniciais}

Subjetividade e ironia são termos que, tanto do ponto de vista teórico quanto do ponto de vista do senso comum, não encontram consenso em suas definições. Do ponto de vista do senso comum, o termo ironia é caracterizado como uma figura de linguagem e de pensamento por meio da qual aquele que fala visa a levar seu interlocutor a entender exatamente o contrário do que o sentido literal de suas palavras expressa. O conteúdo positivo, equivalente ao dito, serviria para realçar ou demonstrar o conteúdo não dito, ou aquilo que se pensa. A definição de ironia compartilhada pelo senso comum embasa-se em outros pontos de vista a respeito da linguagem, também de comum aceitação: primeiramente, a ideia de que as palavras têm um sentido literal, seja pelo fato de considerar a ironia como uma figura de linguagem, seja pelo fato de afirmar que ela comunica um conteúdo a partir do qual haveria um sentido derivado; e, em segundo lugar, a ideia de que as palavras da língua remetem a elementos da realidade mundana ou psicológica, que lhe seriam exte- riores, no caso, a expressão de um pensamento. Tal concepção do senso comum a respeito da ironia encontra eco na definição trazida pelo dicionário Houaiss para o termo:

ironia s.f. (s XV cf. FichIVPM) 1 RET figura por meio da qual se diz o contrário do que se quer dar a entender, uso de palavra ou frase de sentido diverso ou oposto ao que deveria ser empr., para definir ou denominar algo [A ironia ressalta do contexto.] (...) 2 m.q. ASTEÍSMO ('uso sutil e delicado da crítica irônica') (...) 4 p. ext. uso de palavra, expressão ou acepção de caráter sarcástico; zombaria. (HOUAISS, 2001, p. 1651, grifos no original).

A subjetividade, segundo o que comumente se afirma, é um conceito amplo, que diz respeito não apenas à linguagem, mas ao ser humano, como um ser social e psicológico. A ideia da subjetividade está ligada, portanto, àquilo que emana do indivíduo: suas crenças, seu modo de ver o mundo, seu espaço íntimo.

Tais definições, entretanto, ao serem confrontadas com os usos reais da linguagem, mostram-se insuficientes, 
pois tanto a subjetividade quanto a ironia são fenômenos complexos e podem receber múltiplas descrições e explicações, a depender do viés teórico a partir do qual as analisamos.

A Teoria da Argumentação na Língua (ANL), que embasará nossa análise, opõe-se de modo contundente às posições do senso comum a respeito tanto da subjetividade, quanto da ironia. Primeiramente, com relação à subjetividade, Oswald Ducrot, um dos idealizadores da ANL, postula que a subjetividade é inerente à linguagem, ou seja, lhe é constitutiva. Tal caráter se fundamenta na oposição à concepção tradicional de sentido, que vê na linguagem indicações objetivas, subjetivas e intersubjetivas. Já a definição de ironia dada pelo senso comum é rejeitada pelo autor em função da sua própria concepção subjetiva da linguagem: para Ducrot, as palavras não representam realidades psicológicas ou mundanas, nem mesmo teriam um sentido literal do qual sentidos metafóricos seriam derivados. As palavras da língua têm seu sentido construído no uso, através da atividade de fala de um locutor.

Subjetividade e ironia, portanto, serão objeto de discussão nestas páginas, especificamente, segundo a abordagem da Argumentação na Língua. Primeiramente, discutiremos a construção da concepção subjetiva da linguagem por Oswald Ducrot, a partir da refutação feita pelo autor à concepção tradicional de argumentação e à descrição tradicional do sentido e da proposição da Teoria da Polifonia. Em um segundo momento, abordaremos alguns conceitos constitutivos da Teoria da Polifonia, bem como o modo pelo qual explica enunciados irônicos através da distinção de diferentes funções desempenhadas pelo sujeito falante. Em um terceiro momento, traremos alguns conceitos necessários à análise linguística, que compõem a Teoria dos Blocos Semânticos (fase atual da ANL). Por fim, analisaremos uma crônica humorística, de autoria indefinida, a fim de verificar o modo como tais conceitos operam na explicação do sentido irônico dos enunciados.

\section{Sobre a construção da concepção subjetiva da linguagem na Teoria da Argumentação na Língua}

Nesta seção, traçaremos o percurso pelo qual se deu a construção da concepção subjetiva da linguagem na Teoria da Argumentação na Língua (ANL) pela explanação de alguns conceitos que lhe são fundamentais, bem como pelo trajeto pelo qual a ANL passou para que se constituísse como uma ferramenta de estudo da linguagem, com foco em seu aspecto semântico.

A Teoria da Argumentação na Língua surge, em meados da década de 70, como uma proposta de oposição à concepção tradicional de sentido, que via na linguagem três aspectos de natureza distinta: um aspecto objetivo, que lhe conferiria a propriedade de falar do mundo exterior a ela com completa imparcialidade; um aspecto subjetivo, que dizia respeito à posição que o locutor assumiria diante daquilo de que fala; e um aspecto intersubjetivo, que estaria constituído pela relação que o locutor mantém com o seu interlocutor, distinção essa usada especialmente pelo alemão Karl Bühler (DUCROT, 1990).

Jean-Claude Anscombre e Oswald Ducrot, idealizadores da ANL, recusam, dentre essas três indicações sobre o sentido, a distinção entre o aspecto objetivo e subjetivo, pois acreditam que a linguagem não dá acesso à realidade de forma objetiva, mas que a realidade consiste apenas em um tema para debate entre dois indivíduos (DUCROT, 1990, p. 50). Para Ducrot (1990), apenas os aspectos subjetivo e intersubjetivo são constitutivos do sentido, e, juntos, compõem o valor argumentativo de uma entidade linguística. É o valor argumentativo que define a orientação que tal entidade dá ao discurso, e como está presente em todas os signos da língua, o emprego desse ou daquele vocábulo determina a continuação que se dará ao discurso. $\mathrm{O}$ valor argumentativo está constituído, portanto, pelo conjunto das possibilidades de continuação que se pode dar a um discurso e, por isso, é considerado como o nível fundamental de descrição do sentido, sendo por meio dele que se explica a ilusão de que as palavras possuem um valor factual real (DUCROT, 1990).

Oswald Ducrot não integra em suas pesquisas semânticas descrições nas quais a linguagem seja vista como um meio de transmitir informações sobre a realidade, passíveis de avaliações em termos de verdade e falsidade. No entendimento da concepção veritativa da linguagem, o sentido das palavras estaria constituído pela capacidade que essas possuiriam de veicular uma informação acerca daquilo de que se fala, fazendo predominar o caráter objetivo, que lhe conferiria a propriedade de descrever os fatos tal como se apresentam.

A fim de rebater a ideia de que a linguagem seria objetiva e informativa, Ducrot recorre à análise intralinguística, orientação dada pela filiação de sua teoria aos estudos saussurianos da linguagem, conforme o próprio autor afirma:

atribuindo à ordem linguística um caráter irredutível, proibindo-a de fundar-se num outro nível de realidade, Saussure estabelece, a um só tempo, a legitimidade e a necessidade de procurar nela própria o princípio da sua racionalidade. (DUCROT, 1987a, p. 68).

Nesse tipo de análise, o estudo dos elementos linguísticos se dá apenas com base nos enunciados efetivamente produzidos: a pesquisa extralinguística se dá unicamente quando o enunciado não contiver os dados 
linguísticos necessários à sua descrição semântica. Para o autor, a noção de verdade ou falsidade que os enunciados aparentam ter pode ser explicada pelo fato de que o locutor colocou em seu enunciado, por meio de marcas, diferentes Pessoas, garantias do conteúdo evocado e dito pelos/nos enunciados, o que se verifica pela Teoria Argumentativa da Polifonia, sobre a qual falaremos na próxima seção. Ducrot afirma que "o que os linguistas chamam realidade é simplesmente aquilo que, segundo eles, é objeto de outras ciências sobre as quais se descarrega a obrigação de provar" (DUCROT, 2004, p. 370) (tradução nossa) ${ }^{1}$.

Considerando a língua como uma forma de construir discursos e não como um meio de dar informações acerca da realidade, o linguista pretende opor-se, ainda, à concepção tradicional de argumentação. Tal concepção argumenta que os enunciados do discurso se encontram embasados nos fatos que veiculam, suas estruturas linguísticas têm por função semântica a descrição factual, sendo a função semântica meramente informativa. Vejamos o esquema discutido por Ducrot (1990, p. 75).

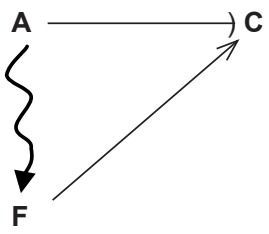

Figura 1. Concepção tradicional de argumentação Fonte: Ducrot (1990, p. 75).

No caso ilustrado pela Figura 1, um discurso argumentativo precisa satisfazer a algumas condições, quais sejam, possuir dois segmentos, um denominado argumento (A) e outro denominado conclusão (C). A deve indicar um fato $\mathbf{F}$, que confere ao argumento $\mathbf{A}$ a possibilidade de ser falso ou verdadeiro. Já a conclusão $\mathbf{C}$ pode ser inferida a partir do fato $\mathbf{F}$. Nessa concepção tradicional da argumentação, é possível perceber que o papel desempenhado pela linguagem é reduzido, visto que o laço que une $\mathbf{A}$ e $\mathbf{C}$ não tem relação alguma com a língua, apenas com o fato que ela veicula. Essa concepção se caracteriza pela exterioridade à linguagem, pois busca nos fatos do mundo a motivação para as conclusões, que, por sua vez, são suscetíveis de serem falsas ou verdadeiras. Para Ducrot, essa concepção invalida o papel da linguagem, que se torna apenas um instrumento do qual os sujeitos se servem para falar sobre o que a ela é exterior

Essa oposição adotada pelo linguista surgiu no momento em que passou a observar que alguns enunciados derivavam do mesmo fato, no entanto, apresentavam

\footnotetext{
"Lo que los lingüistas llaman 'realidad' es simplemente aquello que, según ellos, es el objeto de otras ciencias sobre las que se descarga la obligación de probar". (DUCROT, 2004, p. 370).
}

conclusões diferentes, em especial pela introdução de operadores argumentativos como роисо е ит роисо. Imaginemos uma situação na qual uma pessoa se encontra enferma e, para recuperar sua saúde, necessita alimentar-se. Nesse caso, podemos ter dois enunciados:

(1) Pedro comeu pouco.

(2) Pedro comeu um pouco.

No enunciado (1), a conclusão que se pode tirar é Pedro comeu pouco, portanto não está melhorando, e para o enunciado (2), a conclusão seria oposta, Pedro comeu um pouco, portanto está melhorando. É importante observarmos que ambos os enunciados traduzem o mesmo fato, ou seja, Pedro comeu uma pequena quantidade, no entanto, o que permite que a conclusão não seja a mesma para os dois enunciados são as palavras pouсо e uт роисо, denominadas pelo autor de expressões argumentativas. Essas expressões apresentam a função de determinar que segmentos podem ser relacionados àquele primeiro, já que, para Ducrot, não há a possibilidade de segmentos de discurso expressarem sentido se não estiverem relacionados uns aos outros.

Além da oposição à concepção tradicional de argumentação e à concepção tradicional de sentido, cujo embasamento a ANL encontra em sua base estruturalista, um terceiro aspecto é fundamental para a construção de uma concepção subjetiva de linguagem: a análise vertical permitida pela polifonia, fenômeno que acontece no uso da língua.

Para chegar à construção de uma teoria que desse conta da natureza polifônica da linguagem, Ducrot (1989, 1990) percorre as ideias de Port Royal, Charles Bally e dos filósofos da linguagem, em especial, John Searle, que tratam da distinção entre um aspecto objetivo e um aspecto subjetivo, ligados ao uso da língua. Nas palavras do autor, toda a atividade social realiza, frente a seu exercício, uma imagem de si mesma, e não é diferente com a atividade de fala (DUCROT, 1990, p. 153): essa imagem se materializa na própria linguagem através de palavras que remetem a ela, como significar, dizer, afirmar, etc., caracterizandose com uma representação do que se faz quando se fala.

A concepção veritativa da linguagem, conforme já afirmamos acima, ao tratar da noção de objetividade, tem como função primordial dar uma representação da realidade, e seu valor fundamental seria o valor informativo, o que significa dizer que o sentido pode ser julgado em termos de verdade e falsidade. Tal concepção, segundo Ducrot, já havia sido parcialmente criticada, especialmente pela Gramática de Port Royal e pela Estilística desenvolvida por Charles Bally, em cujas bases estaria o princípio cartesiano do pensamento: a distinção entre o entendimento e a vontade. $\mathrm{O}$ entendimento 
diz respeito ao modo como as ideias representam (ou podem representar) as coisas; a vontade, por ser ativa, toma decisões e adota atitudes em relação a essas representações (DUCROT, 1989, 1990). Segundo esse ponto de vista, um enunciado, expressão do pensamento, tem seu sentido constituído por um modus e um dictum: o modus representa a atitude da vontade, enquanto o dictum amalgama as representações do entendimento. Em um enunciado imperativo (3) Feche a janela!, desceve-se a presença de um modus "quero" aplicado a um dictum, que representa a ação que o enunciado comenta. Entretanto, segundo Ducrot, a crítica apresentada por Port Royal e por Bally mostra-se insuficiente pelo fato de o elemento modal ser, ainda, um tipo de representação: ambos os elementos, o modus e o dictum, seriam de natureza informativa, ainda que de realidades diferentes - a do eu e a do mundo.

Do mesmo modo, argumenta Ducrot (1989, 1990), opera a Teoria dos Atos de Fala, especificamente na fase desenvolvida por Searle, ao descrever o sentido do enunciado como a aplicação de uma força ilocucionária a um conteúdo proposicional. Tal distinção entre esses dois níveis introduziu uma distinção entre um aspecto subjetivo e um aspecto objetivo, ou, entre o modus e o dictum. Tomando o exemplo apresentado anteriormente, em (3) Feche a janela!, pela Teoria dos Atos de Fala, descreve-se nele uma força ilocucionária de "ordem", ou um modus "quero"; do mesmo modo, em uma asserção do tipo (4) Faz bom tempo, descreve-se uma força ilocucionária de "afirmação" e um modus "creio". Asserção e ordem, portanto, apenas comentam a enunciação, ou indicam em que ela consiste, não dão informações acerca da realidade, e, por não terem esse caráter referencial, escapam ao julgamento de verdade ou falsidade.

Ducrot coloca, entretanto, que a Teoria dos Atos de Fala, tal como a concebeu Searle, renuncia a esse princípio de não referencialidade com relação à força ilocucionária ao introduzir o conceito de "condições de felicidade", caracterizado como um conjunto de condições que necessitam ser satisfeitas para que o ato ilocutório se realize. Dentre as condições apresentadas por Searle, Ducrot (1990) menciona a hierarquia que deve haver entre o locutor e o destinatário para que o ato ilocucionário possa ter uma realização institucional, colocando, dessa forma, tal ato como pertencente à realidade objetiva.

Para Ducrot, os filósofos da linguagem não eliminaram totalmente o aspecto objetivo da linguagem, mas separaram o aspecto referencial do pragmático: a significação, segundo essa concepção teórica, está constituída por dois componentes bem delimitados: um aspecto subjetivo, que caracteriza a força ilocucionária, e um aspecto objetivo, ocupado pelo conteúdo proposicional. (DUCROT, 1990, p. 158). A crítica do autor fundamenta-se, principalmente, no fato de essa distinção apresentar-se como insustentável, pois não haveria como afirmar que a linguagem encerra em sua significação um aspecto puramente objetivo, que não esteja contaminado com intenções pragmáticas.

Como resultado concreto da insatisfação com o tratamento dado à linguagem pelos autores mencionados acima, Ducrot propõe uma concepção do sentido que invalide a concepção veritativa, através do conceito de polifonia, que permite a análise vertical dos enunciados e mostra que, por trás da aparente realidade monológica, a linguagem traz uma realidade dialógica.

\section{Sobre a Teoria Argumentativa da Polifonia (TAP) e o conceito de ironia}

\subsection{Alguns conceitos da TAP}

A Teoria Argumentativa da Polifonia inscreve-se no quadro teórico geral da Teoria da Argumentação na Língua e dá conta dos aspectos enunciativos do sentido dos enunciados. Ela tem por objetivo estudar os laços que existem entre a descrição do conteúdo do enunciado e a apresentação que o locutor faz desse conteúdo.

A ideia principal da teoria da polifonia é opor-se ao princípio de unicidade do sujeito falante e incorporar às suas explicações sobre o uso da língua "algumas pistas para a descrição de certos fenômenos que mostram alusões do enunciado a enunciações diferentes da sua" (CAREL; DUCROT, 2010, p. 9).

O conceito de polifonia aparece como uma forma de rebater a concepção veritativa da linguagem. Para Ducrot, a polifonia é apresentada como uma espécie de diálogo cristalizado, uma análise vertical que "atribui a cada um dos componentes uma autonomia enunciativa: cada um constitui a significação de um discurso possível" (DUCROT, 2005, p. 18). Se admitirmos que o sentido do enunciado é um reflexo da sua enunciação, precisamos admitir também que não são as informações que ele comunica acerca do mundo que rodeia o locutor que o constituem semanticamente. O sentido descrito como um espelho da sua enunciação revela esse acontecimento particular da língua, pois a enunciação também é a transformação da língua em discurso pela atividade de fala do locutor que, por meio da sua palavra, dá a conhecer outros discursos que lhe são constitutivos.

$\mathrm{Na}$ cena enunciativa descrita pela TAP, são reconhecidas três entidades, que têm diferentes estatutos linguísticos: o sujeito empírico, o locutor, e as Pessoas.

Ao primeiro deles, sujeito empírico, são atribuídas três características fundamentais: a primeira delas é o fato de ser dotado de uma atividade psico-fisiológica necessária à produção do enunciado; a segunda característica atribuída a ele é o fato de ser o autor, a 
origem dos enunciados; e a terceira característica é a de ser designado em um enunciado pelas marcas de primeira pessoa. Portanto, o sujeito empírico é o autor efetivo do enunciado, é o ser que tem existência no mundo e sobre o qual não há investimento teórico, uma vez que o relevante nos estudos da ANL são os componentes linguísticos e enunciativos do discurso, e não as condições exteriores à sua produção.

O segundo elemento, o locutor, é caracterizado como aquele a quem se imputa a responsabilidade pelo enunciado, uma vez que o locutor deixa nele suas marcas, podendo ser distinto do sujeito empírico, como é o caso de enunciados relacionados por mas, que apresentam dois pontos de vista que se opõem. Trata-se, dessa forma, de um ser teórico a quem se atribui a responsabilidade do enunciado e a quem remete o pronome de primeira pessoa $\mathrm{eu}$.

Já o conceito de Pessoa vem em substituição ao de enunciador proposto por Ducrot (1987b). Esse último conceito foi abandonado por ser considerado por vezes impreciso (como é o caso das críticas feitas pelo grupo escandinavo Scapoline) e por dar margem a interpretações nas quais era visto como fonte enunciativa, papel que deve ser atribuído unicamente ao locutor, único ser teórico que tem o poder de produzir enunciados. Dada a impossibilidade de o locutor relacionar-se diretamente com os conteúdos evocados pelo seu discurso, foi criado o conceito de Pessoa, pois o que importa em realidade não é a identidade dos enunciadores, "mas o modo particular pelo qual eles preenchem o papel geral que lhes é conferido. Consideramos esse papel como o de garantias e chamaremos 'Pessoas' o tipo de garantia ao qual ele recorre."(CAREL; DUCROT, 2010, p. 19) (grifo dos autores).

As pessoas são em número de cinco: a primeira é a voz do próprio locutor, a qual é denominada L. A segunda é a voz do interlocutor, chamada TU. A terceira é a voz do ON (SE), caracterizada como a voz da opinião pública; a quarta, chamada MUNDO, é a voz dos fatos; e, por fim, a quinta pessoa IL (ELE), uma voz mais discreta, a voz distanciada do ausente, sem autoridade (CAREL, 2010, p. 25-26).

Para Carel e Ducrot (2010), a significação dos enunciados deve ser descrita por meio de tripés, chamados unidades de discurso, cada um deles contemplando três elementos: o conteúdo, a pessoa, e as atitudes do locutor. O conteúdo é o sentido do enunciado, que evoca outros conteúdos ou pontos de vista. As atitudes que o locutor tem em relação às pessoas às quais são atribuídos os conteúdos é o que Carel (2011c) dá o nome de funções textuais. Elas dizem respeito ao papel discursivo que o locutor dá ao conteúdo do seu enunciado, podendo ser de três tipos: duas delas positivas, pôr e concordar, e uma negativa, excluir.
O locutor pode pôr o conteúdo quando o faz como objeto de sua enunciação, articulando-o a outro discurso. No entanto, a atitude de pôr um conteúdo não implica necessariamente que a fonte desse conteúdo seja o locutor: ele pode fazer de um conteúdo o objeto de sua enunciação e, no entanto, esse conteúdo ter como fonte uma Pessoa do discurso diferente de L. A segunda atitude que o locutor pode tomar em relação aos conteúdos ditos/ evocados em seu discurso é a de concordar, que se dá, em geral, em relação a conteúdos pressupostos. A terceira atitude, caracterizada como negativa, é a exclusão. Ela acontece quando o locutor rejeita o conteúdo, recusandose a discuti-lo. Essas atitudes são atitudes discursivas, cuja função é dar ao locutor a possibilidade de indicar o papel discursivo que pretende dar ao conteúdo do seu enunciado: não são atitudes psicológicas que revelam as crenças do locutor, mas compõem linguística e enunciativamente o sentido dos enunciados.

A assimilação, presente em outras versões da Teoria da Polifonia (como Ducrot (1990) e Carel e Ducrot (2008)), encontra-se diluída agora na noção de Pessoa, uma vez que nesse conceito já se encontra embutida a fonte a partir da qual determinado conteúdo tem origem.

\subsection{Sobre a descrição de enunciados irônicos}

Oswald Ducrot, no capítulo da obra $O$ dizer e o dito (1987) denominado Esboço de uma Teoria Polifônica da Enunciação, mostra a pertinência da noção de enunciador (aqui tratada como a Pessoa) quando descreve a ironia a partir do artigo de Sperper \& Wilson denominado As ironias como menções ${ }^{2}$ e de um capítulo da obra Elementos de linguística pragmática, de Berrendonner ${ }^{3}$.

Para Ducrot (1987b), a ironia é frequentemente descrita como dizer $X$ para levar a entender $n \tilde{a} o-X$ (tal como sugere a definição para o termo "ironia" dada pelo dicionário Houaiss), descrição esta que sustenta a mudança de um sentido literal do enunciado para um sentido derivado. Este, entretanto, não é o ponto de vista de Sperber \& Wilson. Segundo Ducrot (1987b, p. 197), esses autores sustentam que "um discurso irônico consiste em fazer dizer, por alguém diferente do locutor, coisas evidentemente absurdas" e fazer ouvir a voz de alguém diferente do locutor. Esta tese de S\&W é, entretanto, insatisfatória para Ducrot, pelo fato de usar, para descrever a ironia, o verbo mencionar: Para Ducrot, não há nada de irônico em relatar que alguém sustentou um discurso absurdo.

\footnotetext{
2 Tradução livre que fazemos do título do artigo cuja referência é SPERBER, D. \& WILSON, D. Les ironies comme mentions. Poétique, n. 36, p. 399-412, 1978.

3 BERRENDONNER, A. Éléments de linguistique pragmatique. Minuit: Paris, 1981
} 
É nesse sentido que a distinção entre locutores e Pessoas é pertinente para a explicação de enunciados irônicos. Para serem qualificados como tais, esses enunciados precisam cumprir três condições: (a) Entre os pontos de vista apresentados no enunciado, há pelo menos um que é absurdo, insustentável; (b) O ponto de vista absurdo não é atribuído ao locutor; (c) No enunciado não se expressa nenhum ponto de vista oposto ao ponto de vista absurdo, ou seja, não é retificado por nenhuma Pessoa. O autor denomina irônico o enunciado cujo ponto de vista absurdo é atribuído a um personagem determinado, que se busca ridicularizar (DUCROT, 1990, p. 20-21). Para o autor, é fundamental que o ponto de vista absurdo apresentado pelo locutor não possa ser por este assumido.

Esse "teatro", representado pelos locutores e Pessoas, implica uma determinada imagem da realidade, dando ao aspecto informativo da significação apenas um caráter derivado, destituindo-o do centro da significação.

\section{Sobre alguns conceitos da Teoria dos Blocos Semânticos}

A Teoria dos Blocos Semânticos, fase atual da ANL, desenvolvida por Oswald Ducrot e Marion Carel, caracteriza-se por ser o que os autores denominam de estruturalismo do discurso, fazendo referência ao estruturalismo saussuriano, na medida em que, para os autores, trata-se de descrever o sentido das palavras a partir dos discursos que são evocados a partir delas, e não a partir de fatos (como propõe a concepção tradicional de argumentação) ou de realidades extralinguísticas.

Os empregos atômicos de sentido, considerados como unidades mínimas de sentido na TBS, são os chamados discursos argumentativos, conceituados como o emprego da língua. Teoricamente, a descrição e explicação de seu sentido se dá pelo isolamento dos encadeamentos argumentativos evocados, dos aspectos argumentativos e, finalmente, do bloco semântico, o qual resulta da interdependência entre os dois predicados do enunciado.

Sendo os enunciados da língua a materialização das frases cuja relação é expressa por um conector, um enunciado é teoricamente representado por $X C O N$ $Y$ e X $C O N^{\prime} Y$. Essa representação teórica comporta dois segmentos que têm sua relação expressa por um conector: $X$ corresponde ao primeiro segmento, ao qual Carel e Ducrot (2008) atribuem o nome de suporte. A $Y$, é atribuída a designação de aporte. $C O N$ e $C O N$ ' são os dois tipos de conectores que podem intervir na relação entre os segmentos: o primeiro deles - CON é do tipo normativo, representado por donc, do francês portanto, cuja sigla é DC e engloba uma categoria de conjunções: se, por isso, já que; o segundo - CON’- do tipo transgressivo é representado por pourtant, do francês no entanto, e engloba uma série de conjunções como mas, entretanto, mesmo se, apesar de.

A interdependência entre os segmentos de um enunciado tem por resultado a construção de um conteúdo que os autores denominam bloco semântico, e aos modos de apreendê-lo, denominam aspectos argumentativos. Segundo definição de Carel (2011b),

podemos discernir em cada predicado argumentativo [aspecto argumentativo], um modo e um conteúdo: é o conteúdo que é atômico, e ele apenas será qualificado de "bloco semântico", e é dele que os predicados argumentativos [aspectos argumentativos] partilharão. (CAREL, 2011b, p.60) (tradução nossa, grifo do autor $)^{4}$.

Os aspectos argumentativos que constituem parte da significação dos enunciados também exprimem a significação dos termos da língua. Ducrot e Carel propõem-se descrever as palavras da língua não por determinados traços, mas por predicados argumentativos ou conjuntos de predicados argumentativos. Esse modo de explicar a significação dos termos busca reassumir o legado saussuriano, que recusa o conhecimento de outro domínio que não seja o da língua para permitir conhecêla, pois ela não se constitui um reflexo do domínio não linguístico.

Tomemos alguns exemplos de argumentações transgressiva e normativa: (5) Se tu não fizeres o dever de casa, não irás ao cinema amanhã; (6) Mesmo se tu fizeres o dever de casa, não irás ao cinema amanhã; (7) Se tu não fizeres o dever de casa, não irás bem na prova. Tanto (5) quanto (6) constituem julgamentos elementares feitos por um locutor, ou argumentações. (5) é do tipo normativo, representado pelo aspecto (5a) falta DC punição; (6) é transgressivo, cujo sentido é expresso pelo aspecto (6a) neg falta PT punição; e (7a) falta DC neg sucesso. Devese notar que a interdependência estabelecida entre os dois segmentos dos dois primeiros enunciados é a mesma; a diferença em cada um deles reside no modo de apreender e expressar esse sentido. (5a) e (6a) são fabricados a partir de uma noção de falta - falta-punível, diferente daquela fabricada por (7a) - falta-fracasso. Poderíamos dizer que (6a) expressa punição-mesmo-sem-falta, enquanto (7a) expressa insucesso-por-causa-da-falta. Diremos que a falta intervém de modo diferente em cada um dos modos de construir o sentido, que, segundo Carel (2011b), são dois diferentes sentidos argumentativos.

\footnotetext{
4 "on peut discerner dans chaque prédicat argumentatif un mode et un contenu: c'est le contenu qui est atomique, et lui seul, il sera qualifié 'bloc sémantique' et c'est lui que partageront les prédicats argumentatifs" (CAREL, 2011b, p. 60).
} 
Tanto a expressão de um sentido normativo, quanto de um transgressivo, portanto, demonstra a vocação predicativa da linguagem. dados.

Vejamos como tais conceitos operam na análise dos

\section{Análise polifônica do discurso}

Tendo este trabalho o duplo objetivo de discutir teoricamente a concepção subjetiva da linguagem, apresentar a explicação dada por Ducrot (1987b, 1990) ao fenômeno da ironia, apresentaremos uma análise de um discurso irônico, que circula na rede e tem como título: O professor está sempre errado ${ }^{5}$.

Utilizaremos como critério de segmentação dos enunciados a proposição apresentada em Ducrot (1990), que define o enunciado como constituído pela presença de dois segmentos (frases, na acepção teórica) relacionados por um conector.

\section{O PROFESSOR ESTÁ SEMPRE ERRADO}

Se é jovem, não tem experiência.

Se é velho, está superado.

Se não tem automóvel, é um pobre coitado.

Se tem automóvel, chora de barriga cheia.

Se fala em voz alta, vive gritando.

Se fala em tom normal, ninguém escuta.

Se não falta ao colégio, é um caxias.

Se precisa faltar, é um turista.

Se conversa com os outros professores, está malhando os alunos.

Se não conversa, é um desligado.

Se dá muita matéria, não tem dó do aluno.

Se dá pouca matéria, não prepara os alunos.

Se brinca com a turma, é metido a engraçado.

Se não brinca com a turma, é um chato.

Se chama a atenção, é um grosso.

Não chama a atenção, não sabe se impor.

Se escreve muito, não explica.

Se explica muito, no caderno não tem nada.

Se fala corretamente, ninguém entende.

Se fala a 'língua' do aluno, não tem vocabulário.

Se a prova é longa, não dá tempo.

Se a prova é curta, tira as chances do aluno.

Se exige, é rude.

Se elogia, é debochado.

Se o aluno é reprovado, é perseguição.

Se o aluno é aprovado, deu mole.

É, o professor está sempre errado, mas se você conseguiu ler até aqui, agradeça a ele!

\footnotetext{
Agradecimentos especiais à Prof. ${ }^{a}$ Dr. ${ }^{a}$ Telisa Furlanetto Graeff pela valiosa contribuição quando da apresentação deste trabalho, ainda em forma de comunicação oral, no II Seminário sobre Discurso e Argumentação, realizado na UFMG, Belo Horizonte, em novembro de 2014.
}

Nossa metodologia segmentará o discurso em enunciados, aos pares, cujos aspectos argumentativos compartilhem o primeiro segmento, ou o suporte. Uma análise preliminar nos leva a pensar que cada enunciado representa uma argumentação externa, ou uma continuação dada ao segmento ser professor: ser um professor jovem, ser um professor que tem carro, ser um professor velho, etc; nos leva a pensar, ainda, que cada enunciado, por outro lado, constitui uma argumentação interna, ou seja, uma paráfrase, de estar sempre errado, segmento presente no título do discurso. A representação que cada enunciado dá de uma argumentação interna a estar sempre errado, acreditamos, justifica por que esse discurso pode ser considerado como absurdo, atendendo, desse modo, ao primeiro critério que Ducrot (1990) utiliza como determinante para um discurso irônico.

Iniciaremos pela análise do título: $O$ professor está sempre errado. Ele é importante na medida em que a palavra sempre, no segmento está sempre errado, atribuído ao professor, funcionaria como um impedimento de justificar que, em algum momento, o professor poderia estar certo (e desfazer, portanto, a absurdez que seu sentido expressa). Para construir o aspecto argumentativo que representa teoricamente o enunciado em questão, nós nos embasaremos em Carel (2005), quando a autora trata dos tipos de predicação. Identificamos aqui uma predicação centrada no grupo verbal, uma vez que os aspectos argumentativos evocados são provenientes deste segmento do enunciado: (a) neg adequar-se às expectativas DC ser criticado, aspecto argumentativo que evoca o seu recíproco, pertencente ao mesmo bloco semântico (b) adequar-se às expectativas DC neg ser criticado. A análise polifônica mostra que o Locutor põe o aspecto argumentativo (a), que representa o conteúdo dito, do qual o locutor dá como origem a pessoa $\mathrm{ON}(\mathrm{SE})$; mostra, também, que o locutor exclui o aspecto argumentativo (b). Tal exclusão do conteúdo (b) justifica-se pelo uso do termo sempre presente no enunciado-título do discurso, que faz parte do predicado atribuído ao professor. Isso significa, segundo nosso entendimento, que o aspecto argumentativo (b), que consistiria em uma possiblidade de sentido para o termo professor, não é posto pelo locutor em nenhum momento ao longo do discurso, ele é apenas evocado pelo discurso e excluído pelo locutor, conforme esperamos demonstrar com a análise que desenvolveremos.

O primeiro enunciado do discurso Se éjovem, não tem experiência evoca os seguintes aspectos argumentativos: (a1) jovem DC neg experiência; (b1) neg jovem DC experiência, que se apresentam como argumentações externas da palavra jovem e pertencem a um mesmo bloco semântico. A palavra jovem entendemos ser representativa do segmento professor jovem, como demonstram os 
encadeamentos evocados Quando o professor é jovem, ele não tem experiência, e Quando o professor não é jovem, tem experiência. A orientação argumentativa dada ao discurso pelo aspecto argumentativo evocado (b1) aponta para uma argumentação fundamentada no aspecto argumentativo evocado pelo título (b) adequar-se às expectativas DC neg ser criticado, enquanto o aspecto argumentativo (a1) aponta para uma argumentação fundamentada no aspecto argumentativo (a) neg adequar-se às expectativas $D C$ ser criticado, que representa o dito no título do discurso que ora analisamos.

Entretanto, o locutor constrói, a partir do segundo enunciado do discurso Se é velho, está superado um novo bloco semântico, que se materializa nos aspectos argumentativos (a2) neg jovem DC superado; (b2) jovem DC neg superado, dando ao segmento jovem uma nova argumentação externa e construindo uma nova interdependência semântica, que também encontra fundamento nos aspectos argumentativos (a) e (b), construídos a partir do título. Os aspectos argumentativos (a1) jovem $\mathbf{D C}$ neg-experiência e (a2) neg-jovem DC superado seriam, portanto, argumentações internas do segmento estar sempre errado, presente no título.

Com relação à análise polifônica, podemos afirmar que os aspectos argumentativos (a1) e (a2) representam os conteúdos ditos no primeiro e no segundo enunciados, conteúdos que o locutor põe, mas cujas garantias não são dadas pela Pessoa L, e sim, pela Pessoa ON (SE), caracterizada por Carel $(2010$, p. 24) como a voz da opinião pública. Já os aspectos argumentativos (b1) e (b2) representam os conteúdos evocados pelo primeiro e segundo enunciados, conteúdos que o locutor exclui e que tem como garantia a pessoa MUNDO, ou a voz dos fatos, tratando-se aqui de um fato linguístico, uma vez que tal conteúdo é evocado a partir de uma marca linguística específica, o termo se.

Não sendo o locutor a garantia do conteúdo dito, mas sim a Pessoa ON(SE), acreditamos verificar-se o segundo critério estabelecido por Ducrot (1990) para a caracterização de discursos irônicos: o conteúdo absurdo apresentado ou posto pelo locutor não é sustentado por este, ou não lhe é atribuído: em nossa análise, identificamos como garantia do conteúdo posto a voz da opinião pública, ou seja, discursos que circulam a respeito do professor, que são compartilhados, mas dos quais o locutor não toma parte, apenas reproduz, sem os assumir.

Consideraremos como suficiente a análise dos dois primeiros enunciados do discurso, visto que os demais enunciados, à exceção do último, obedecem à mesma construção: há um aspecto argumentativo que representa o dito e um aspecto argumentativo que representa o não dito, construindo argumentações externas para a generalização ser professor $X$ DC motivo pelo qual está errado, discursos estes que representam, portanto, argumentações internas ao título.

$\mathrm{O}$ último enunciado do discurso $\dot{E}$, o professor está sempre errado, mas se você conseguiu ler até aqui, agradeça a ele apresenta alguns aspectos interessantes que merecem destaque nesta análise: primeiramente, a asserção realizada pelo locutor $E$, o professor está sempre errado. Apesar de o locutor pôr esse conteúdo, como nos enunciados anteriores, ele continua não se apresentando como sendo sua garantia, mas sim, apresenta a Pessoa ON(SE) como garantia, ou seja, a voz da opinião pública. Em segundo lugar, a aparente suposição (o que Dall Cortivo (2013) denominou suposição formal) construída pelos segmentos se você conseguiu ler até aqui, agradeça a ele não é, de fato, uma suposição, mas uma afirmação, já que nada é colocado no nível hipotético. Acreditamos que o locutor põe tal conteúdo e dele se coloca como garantia, ou seja, a Pessoa fonte deste último conteúdo é o LOCUTOR.

Este último enunciado tem uma construção diferente dos demais e, acreditamos, atende ao terceiro critério estabelecido por Ducrot (1990) para caracterização dos enunciados irônicos: não há a apresentação de um ponto de vista oposto aos pontos de vista absurdos apresentados, o locutor não afirma "veja bem, o professor não está errado", ele apenas sugere isso quando se dirige a um interlocutor qualquer que lê seu texto, aconselhando-o a agradecer ao professor por ter conseguido lê-lo.

Como um último quesito apontado por Ducrot (1990) como fundamental para a caracterização de enunciados como irônicos, há a necessidade de atribuir o enunciado absurdo, no caso, o discurso de modo geral, a alguém que se queira ridicularizar. A pessoa a quem o locutor deseja ridicularizar, segundo nosso ponto de vista, não é alguém determinado, mas sim, uma espécie de coletividade, que cristaliza em seus discursos, sentidos como esses construídos pelos enunciados que analisamos, ou, a Pessoa ON(SE). Como afirmamos no início desta análise, a ausência de possibilidade de o professor estar certo em algum momento, ou seja, de atender às expectativas que nele se depositam, impossibilidade esta que se dá sempre pela proposição de um novo bloco semântico e de uma nova argumentação externa ao segmento ser um professor $X$, tornam o discurso absurdo e, por fim, irônico.

\section{Considerações finais}

Pretendemos, ao longo destas páginas, tratar da ironia e do aspecto subjetivo da linguagem. Pode estar questionando-se o leitor: qual é a relação entre subjetividade e ironia? Por que tais conceitos foram escolhidos para figurar estas linhas? Em que se aproximam ou se distanciam?

Inicialmente, acreditamos poder afirmar que subjetividade e ironia se distanciam em um aspecto 
crucial: a subjetividade é constitutiva da linguagem, enquanto a ironia constitui-se um uso da língua. Sendo a subjetividade constitutiva da linguagem, ela estará presente em qualquer que seja o uso que os locutores dela fizerem: seja por meio de enunciados humorísticos, seja por meio de enunciados negativos, seja por meio de enunciados irônicos. Subjetividade, ao contrário da ironia, não se constitui como um objeto de análise, mas como um princípio: qualquer que seja a análise feita da linguagem deverá levar em conta o seu aspecto subjetivo.

É aí que pensamos residir, paradoxalmente, a estreita relação entre a ironia e a subjetividade: a segunda está contida na primeira. Retomamos aqui uma passagem interessante de um dos capítulos de Ducrot (1990), na qual o autor faz referência a Platão e ao mito socrático da caverna: segundo esse mito, que reproduzimos de forma bastante sintetizada, Sócrates comparava os homens a prisioneiros trancados, desde o seu nascimento, em uma caverna, de costas para o mundo exterior, enxergando apenas o muro à sua frente, onde suas sombras eram projetadas. Sem nunca terem tido acesso à exterioridade, os prisioneiros acreditavam ser aquelas sombras a realidade. Ducrot (1990, p. 170) comprara a caverna à linguagem, e afirma:

Estamos obrigados a utilizá-la e, por causa disso, não podemos conceber proposições capazes de serem falsas ou verdadeiras. Por esta mesma razão, só podemos ter pontos de vista argumentativos. (DUCROT, 1990, p. 170) (tradução nossa) ${ }^{6}$.

A concepção subjetiva da linguagem impossibilita que os enunciados sejam tomados como verdadeiros ou falsos, mas apenas como pontos de vista a respeito dos fatos, ou como as sombras projetadas no fundo da caverna - não são a realidade, mas representações desta. Discursos sobre o professor são construídos e têm como garantias diferentes Pessoas, entretanto, tais discursos colocam-se como um debate a respeito dessa figura, sem que um ou outro possa ser considerado como verdadeiro ou falso, mas apenas como objeto de asserção de determinados locutores. Tais pontos de vista podem ser expressos por um locutor através de diferentes usos da língua, sendo um deles a ironia: podemos, ao mesmo tempo que manifestamos implicitamente nosso ponto de vista, rejeitar ou ridicularizar aqueles que rivalizam com nossos modos de apreender a realidade. Acreditamos que a ironia, tal como descrita por Ducrot, constitui-se um excelente exemplo de como a linguagem é subjetiva e de como é importante a distinção de diferentes personagens na enunciação. Se não levássemos em conta esses dois aspectos, o discurso que ora analisamos receberia uma

\footnotetext{
6 Estamos obligados a utilizarlo, y a causa de esto no podemos concebir proposiciones capaces de ser falsas o verdaderas. Por esta misma razón, solo podemos tener puntos de vista argumentativos. (DUCROT, 1990, p. 170)
}

descrição insatisfatória, pois se acreditaria que o locutor se colocou como origem do dizer e como garantia, sendo esse dizer uma descrição objetiva da figura do professor. Parece-nos que não são descrições do professor que encontramos no sentido do discurso aqui analisado.

\section{Referências}

CAREL, Marion. La predicación centrada. In: CAREL, Marion; DUCROT, Oswald. La semántica argumentativa: una introducción a la Teoría de los Bloques Semánticos. Buenos Aires: Ediciones Colihue, 2005. p. 127-147.

CAREL, Marion, DUCROT, Oswald. Descrição argumentativa e descrição polifônica: o caso da negação. Letras de Hoje, Porto Alegre, v. 43, n. 1, p. 7-18, jan./mar. 2008.

CAREL, Marion; DUCROT, Oswald. Atualização da polifonia. Desenredo - revista do programa de Pós-Graduação em Letras da Universidade de Passo Fundo, Passo Fundo, v. 6, n. 1, p. 9-21, jan./jun. 2010.

CAREL, Marion. Polifonia e argumentação Desenredo - revista do programa de Pós-Graduação em Letras da Universidade de Passo Fundo, Passo Fundo, v. 6, n. 1, p. 22-36, jan./jun. 2010.

CAREL, Marion. La polyphonie linguistique. Transposition - musique et sciences sociales, Paris, EHESS, n. 1, 2011a. Disponível em: <http://transposition-revue.org/les-numeros/ polyphonie-et-societe/article/la-polyphonie-linguistique $>$. Acesso em: 23 nov. 2014.

CAREL, Marion. L'entrelacement argumentatif. Paris: Honoré Champion, 2011b.

CAREL, Marion. Attribution de point de vue et effacement du récit. In: CORMINBOEUF, Gilles; BÉGUELIN, MarieJosé Béguelin (Éds.). Du système linguistique aux actions langagières. Mélanges en l'honneur d'Alain Berrendonner. Bruxelles: De Boeck/Duculot, 2011c.

DALL CORTIVO, Cristiane. O estudo da suposição no quadro da Teoria dos Blocos Semânticos e da Teoria da Argumentação Polifônica. $181 \mathrm{f}$. Tese (Doutorado em Linguística e Letras) Pontifícia Universidade Católica do Rio Grande do Sul, Porto Alegre, 2013.

DUCROT, Oswald. Estruturalismo, enunciação e semântica. $O$ dizer e o dito. Campinas: Pontes, 1987a.

DUCROT, Oswald. Esboço de uma teoria polifônica da enunciação. O dizer e o dito. Campinas: Pontes, $1987 \mathrm{~b}$.

DUCROT, Oswald. Énonciation et polyphonie chez Charles Bally. Logique, structure, énonciation. Paris: Minuit, 1989.

DUCROT, Oswald. Polifonía y argumentación: conferencias del seminario Teoría de la Argumentación y Análisis del Discurso. Cali: Feriva, 1990.

DUCROT, Oswald. Sentido y argumentación. In: ARNOUX, Elvira N.; NEGRONI, Maria M. Homenaje a Oswald Ducrot. Buenos Aires: Eudeba, 2004.

DUCROT, Oswald. A pragmática e o estudo semântico da língua. Letras de Hoje, Porto Alegre, v. 40, n. 1, p. 9-21, 2005. HOUAISS, A. Dicionário Houaiss da língua portuguesa. Rio de Janeiro: Objetiva, 2001.

Recebido: 30 de novembro de 2014

Aprovado: 13 de fevereiro de 2015

Contatos: cristianedc@unisc.br adilson.ventura@gmail.com 